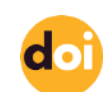

http://doi.org/10.22282/ojrs.2021.86

\title{
TAEKWON-DO SPORCULARININ BESLENME TUTUMLARININ ÇEŞITLİ DEĞISTKENLER AÇISINDAN İNCELENMESİ
}

\author{
Özgür GÜLEN ${ }^{1}$, Mehmet KUMARTAŞLI ${ }^{2}$, Enes MADAK ${ }^{3}$ \\ Hüseyin Ozan SÖNMEZ ${ }^{3}$, Osman PEPE ${ }^{2}$ \\ ${ }^{1}$ Yalova Gençlik ve Spor İl Müdürlüğü, Türkiye \\ ${ }^{2}$ Süleyman Demirel Üniversitesi, Spor Bilimleri Fakültesi, Türkiye \\ ${ }^{3}$ Milli Savunma Üniversitesi, Deniz Harp Okulu, Türkiye
}

\section{ÖZET}

$\mathrm{Bu}$ çalışma taekwondo sporcularının çeşitli değişkenler açısından beslenme tutumlarının incelenmesi amacıyla yapılmıştır. Araştırmaya Türkiye'nin farklı ilerinden taekwondo branşında ki farklı yaş gruplarından seçilen \%72,4'ü erkek $(n=157)$ ve \%27,6's1 kadın $(n=60)$ toplam 217 sporcu katılım sağlamış olup, sporcuların \%29,5'i $(\mathrm{n}=64)$ milli sporcu ve $\% 70,5^{\prime} \mathrm{i}(\mathrm{n}=153)$ ise milli sporcu değildir. Sporcuların beslenmeye ilişkin tutumlarını değerlendirmek amacıyla 21 sorudan oluşan "Sağlıklı Beslenmeye İlişskin Tutum Ölçeği” uygulanmıştır. Verilerin analizinde SPSS Statistics 23 paket programı kullanılmıştır. Elde edilen verilerin normallik dağılımlarına bakılmış olup, verilerin normal dağıldığ 1 tespit edilmiştir. Verilerin analizinde tanımlayıcı istatistikler belirlenip, ikili karşılaştırmalarda "Independent Sample T-Test" ve çoklu karşılaştırmalara "One Way Anova Testi" kullanılmıştır. Anlamlılık değeri $\mathrm{P}<0,05$ olarak kabul edilmiştir. Sporcuların beslenmeye ilişkin tutumlarında cinsiyet, millilik ve VKI değişkenine göre istatistiksel olarak anlamlılık görülmezken $\mathrm{P}>0,05$, yaş, spor yapma yılı ve eğitim değişkenine göre istatiksel olarak anlamlılık saptanmıştır $\mathrm{P}<0,05$. Sonuç olarak katılımcıların sağlıklı beslenmeye ilişkin tutumlarında cinsiyet, millilik, vücut kitle indeksi değişkenlerinin beslenmeye yönelik tutumlarını etkilemediği ancak eğitim durumu, yaş ve spor yapma yılı değişkenlerinin tecrübeye esas değişkenler olduğundan dolayı katılımcıların beslenmeye yönelik tutumlarında farklılıklara neden olduğu söylenebilir.

Key Words: Taekwondo, Sporcu Beslenmesi, Beslenme Tutumu. 


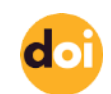

http://doi.org/10.22282/ojrs.2021.86

\title{
AN INVESTIGATION OF THE NUTRITION ATTITUDE OF TAEKWON-DO ATHLETES IN TERMS OF VARIOUS VARIABLES
}

\author{
Özgür GÜLEN ${ }^{1}$, Mehmet KUMARTAŞLI ${ }^{2}$, Enes MADAK ${ }^{3}$ \\ Hüseyin Ozan SÖNMEZ1, Osman PEPE ${ }^{2}$ \\ ${ }^{1}$ Yalova Gençlik ve Spor İl Müdürlüğü, Türkiye \\ ${ }^{2}$ Süleyman Demirel Üniversitesi, Spor Bilimleri Fakültesi, Türkiye \\ ${ }^{3}$ Milli Savunma Üniversitesi, Deniz Harp Okulu, Türkiye
}

ABSTRACT

\begin{abstract}
This study was conducted to examine the nutritional attitudes of taekwondo athletes in terms of various variables. A total of 217 athletes, $72.4 \%$ female $(\mathrm{n}=$ $60)$ and $27.6 \%$ male $(\mathrm{n}=157)$ selected from different age groups in the branch of taekwondo from different parts of Turkey participated in the study and $29.5 \%$ of the athletes $(n=64)$ are national athletes and $70.5 \%(\mathrm{n}=153)$ are not national athletes. In order to evaluate athletes' attitudes towards nutrition, the "Attitude Scale Towards Healthy Nutrition" consisting of 21 questions was applied. SPSS Statistics 23 package program was used in the analysis of the data. The normality distributions of the obtained data were examined and it was determined that the data were distributed normally. Descriptive statistics were determined in the analysis of the data and "Independent Sample TTest" was used for paired comparisons and "One
\end{abstract}

Way Anova Test" was used for multiple comparisons. Significance value was accepted as P $<0.05$. While there was no statistical significance in athletes' attitudes towards nutrition according to gender, nationality and BMI variable $\mathrm{P}>0.05$; according to age, years of doing sports and education variable was found statistically significant $\mathrm{P}<0.05$. As a result, it can be said that the variables of gender, national athletes, body mass index do not affect the attitudes of the participants towards healthy eating, but because the variables of education status, age and years of doing sports are the variables that are the basis for experience, it can be said that they cause differences in the attitudes of the participants towards nutrition.

Key Words: Taekwondo, Sports Nutrition, Nutrition Attitude 


\section{GíRiş}

Spor, kişilere ruhsal ve bedensel olarak doyum sağlamaktadır. Bununla birlikte bireylerin serbest zamanlarını değerlendirmede ve sağlıklarının korunmasında önemli bir faktördür (Günay ve Cicioğlu, 2001). Bütün bu faydaları sağlamada spor tek başına yeterli olmayıp, düzenli ve sağlıklı bir beslenmeyle birlikte etkisinin daha fazla olacağı söylenebilir.

Sporun popüler olmasının yanında, sporcularında popülerliği artmış ve sporcularla ilgili olan konular konuşulmaya, araştırılmaya başlanmıştır. Bu konuların başında ise beslenme gelmektedir. Sporcu için beslenmenin dengeli ve düzenli olması birçok açıdan önemlidir. Müsabaka ya da antrenmandaki performansı, aşırı kilo alıp vermeyi, elektrolit eksilmesinin sonucundaki rahatsızlığın önlenmesi, düzenli olarak sindirim sisteminin çalışması, enerji kaynaklarının yenilenmesi gibi sporcuyu doğrudan ya da dolaylı yoldan etkileyen birçok durum düzenli ve dengeli beslenmeyle sağlanabilmektedir (Ersoy ve diğ. 1987).

Farklı spor branşlarında yarışan sporcuların özel olarak beslenmeleri, çok eski tarihten beri ilgi duyulan bir konudur. Sağlıklı bir yaşamın ve müsabakalara çıkan sporcuların önemli bir parçasını düzenli beslenme sağlamaktadır. Spor yapan çoğu kişi, beslenme hakkında bilgilenmek istemekte ve sporcuların yönelttiği sorular ise çoğunlukla beslenme alanından gelmektedir. Sporcuların beslenmesinde amaç; sporcunun yaşına, cinsiyetine, günlük yapmış olduğu aktiviteye, spor branşına, antrenman saatine, müsabaka dönemine ve hazırlık dönemine göre değişiklik gösteren ve bunlara göre düzenlemeler yapılarak besinlerin düzenli ve dengeli bir şekilde alınmasıdır (Akıncı, 2018

Sporcu beslenmelerinde asıl 00hedef; sporcuların temel özellikleri olan cinsiyeti, yaşı, fiziksel faktörleri, enerji gereksinimleri ve beslenme alışkanlıkları dikkate alınarak dengeli ve yeterli bir şekilde beslenmelerini sağlamaktır (Özdemir, 2010). Kişilerin yeterli ve dengeli düzeyde enerji alımı vücut bileşimlerini dengede tutma veya istenilen düzeyde kalmasına yardımcı olacağı için bir sporcunun beslenmesinde en önemli noktadır (Thomas ve diğ. 2016).

Özellikle öğrenci olan sporcular genel olarak temel öğünlerine dikkat etmeyerek sadece tek ögünle geçiştirdikleri, besin değeri düşük gıdaları daha fazla tükettikleri, yetersiz ve dengeli olmayan beslenmenin maddi zorlukları, yeterli olmayan ve dengesiz beslenmenin sebebi maddi durumun etkisi olduğu, yurtlarda kalan öğrenci ve sporcuların yurt koşullarından kaynaklanan 
beslenme problemleriyle karşılaştığ 1 ve sadece doymak için besin tükettikleri görülmüştür (Durmaz ve ark., 2002; Garibağaoğlu ve ark., 2006; Heşeminia ve ark., 2002). Fakat, bir birey gün içinde sağladı̆̆ı enerjinin \%45-60'ını karbonhidratlardan, \%25-35'ini yağlardan ve \%1020 'sini ise proteinlerden sağlayacak şekilde sağlık beslenme gerçekleştirmesi gerekmektedir. (TC Sağlık Bakanlığı Türkiye Beslenme Rehberi, 2015). Fakat öğrencilerin ve sporcuların beslenmeye ilişkin doğru bildikleri ya da bilmedikleri ekonomik problemlerden kaynaklanan bazı sorunlar, temel öğünleri atlayarak doymak için besin tüketmek, zayıf görünmenin güzellikle bağdaştırılması gibi pek çok yanlış tutum sergiledikleri görülmektedir.

Tutum genel olarak, kişinin dışsal faktörlere bağlı çevresinde herhangi bir olay ya da objeye verdiği tepki hareketi anlamına gelir. Başka bir tanım ile tutum, kişinin bir olgu, olay ya da durum karşısında göstermesi beklenen olası davranış şekli olarak tanımlanabilir (İnceoğlu, 2010). Sporcu beslenmesinin performans ve sağlık açısından çok önemli olduğu bilinmesine rağmen birçok sporcunun bu konuda yeterli bilgiye sahip olmadığı ya da yanlış bilgilere sahip olduğu görülmektedir.

Ulaş ve Genç (2010) yaptığı araştırmada, sağlıklı beslenme davranışları; cinsiyet, yaş, medeni durum, eğitim durumu, sosyoekonomik düzey gibi çok farklı sebeplerden etkilendiğini ortaya koymuştur. Yapılan literatür araştırması sonucunda beslenme tutumuna ilişkin çalışmaların az olmasının yanı sıra, taekwondo sporcularının beslenme tutumunun belirlenmesine yönelik bir çalışmanın olmayışı bu çalışmaya dayanak oluşturmuştur.

$\mathrm{Bu}$ çalışmayla, taekwondo sporcularının sağlıklı beslenmeye ilişkin tutumlarının belirlenmesi için beslenme alıskanlıklarının ve beslenme bilgi düzeylerinin belirlenmesi amaçlanmıştır.

\section{YÖNTEM}

\section{Araştırma Modeli}

$\mathrm{Bu}$ araştırma taekwondo sporcularının beslenme alışkanlıklarının ve beslenme bilgi düzeylerinin belirlenmesi amacıyla nicel araştırma yöntemlerinden tarama modeli kullanılmış olup; veriler anket çalışması yapılarak toplanmıştır. 


\section{Araştırma Grubu}

Araştırmaya, Türkiye genelinde teakwondo sporcularından oluşan 64'ü milli sporcu 60 kadın ve 157 erkek olmak üzere toplam 217 kişi gönüllü olarak katılmıştır. Katılımcılara "Sağlıklı Beslenmeye İlişkin Tutum Anketini'” eksiksiz olarak doldurmaları konusunda bilgilendirme yapılmıştır.

\section{Veri Toplama Aracı}

Araştırma verilerinin toplanmasında Tekkurşun Demir ve Cicioğlu'nun 2019 y1lında geçerlik ve güvenirliğini yaptığı 21 madde ve 4 alt boyuttan oluşan likert tipi bir ölçek olan"Sağlıklı Beslenmeye İlişkin Tutum Ölçeği”, kullanılmıştır. 1 puan "kesinlikle katılmıyorum", 5 puan “"kesinlikle katılıyorum” arasında derecelendirilmiştir.

\section{Verilerin Analizi}

Araştırmada yapılan istatiksel analizler SPSS Statistics 23 paket programı aracılığıyla yapılmıştır. Anketten elde edilen verilere dayalı olarak, anketin Cronbach's alpha iç tutarlılık güvenilirlik katsayısı 0,828 olarak hesaplanmıştır. Buna göre, araştırmada uygulanan aracın güvenilir bir araç olduğu söylenebilir. Verilerin normallik dağılıma bakılıp değerlerin -1,5 ile $+1,5$ değer aralığında olduğu saptanmış olup; verilerin normal dağılım gösterdiği kabul edilmiştir. (Tabachnick ve Fidell, 2013). Gruplar arası ikili karşılaştırmada "Independent Samples T-Test" ve çoklu karşılaştırmalarda "One-Way Anova Testi” uygulanmış olup, anlamlı farklılıkları test etmek için LSD Post Hock Testi'nden yararlanılmıştır. Analiz sonuçları 0.05 anlamlılık düzeyinde değerlendirilmiştir. 


\section{BULGULAR}

Tablo 1: Katılımcılara Yönelik Tanımlayıcı İstatistik Tablosu

\begin{tabular}{|c|c|c|c|}
\hline & & $\mathbf{F}$ & $\%$ \\
\hline \multirow{2}{*}{ Cinsiyet } & Erkek & 157 & 72,4 \\
\hline & Kadın & 60 & 27,6 \\
\hline \multirow{3}{*}{ Yaş } & 20 Yaş Alt1 & 128 & 59,0 \\
\hline & 21-30 Yaş Arası & 68 & 31,3 \\
\hline & 31 Yaş Üstü & 21 & 67,7 \\
\hline \multirow{2}{*}{ Milli Sporcu } & Evet & 64 & 29,5 \\
\hline & Hayır & 153 & 70,5 \\
\hline \multirow{3}{*}{ Spor Yaşı } & 10 Y1l Alt1 & 147 & 22,1 \\
\hline & 11-20 Y1l Aras1 & 48 & 10,1 \\
\hline & 21 Y1l Üzeri & 22 & 40,9 \\
\hline \multirow{3}{*}{$\begin{array}{l}\text { Vücut } \\
\text { İndeksi }\end{array}$} & $16,5-18,5$ & 68 & 31,3 \\
\hline & $18,51-25$ & 116 & 53,5 \\
\hline & $25,01-30$ & 33 & 15,2 \\
\hline \multirow{5}{*}{ Eğitim Durumu } & İlkokul & 23 & 10,6 \\
\hline & Ortaokul & 56 & 25,8 \\
\hline & Lise & 71 & 32,7 \\
\hline & Lisans & 55 & 25,3 \\
\hline & Lisansüstü & 12 & 5,5 \\
\hline \multicolumn{2}{|l|}{ Toplam } & 217 & 100 \\
\hline
\end{tabular}

Tablo 1. incelendiğinde katılımcıların \%72,4.2’ü erkek ( $n=157), \% 27,6$ 'sı kadın $(n=60)$, \%59'u 20 yaş ve altı $(n=128), \% 31,3$ 'ü 21-30 yaş arası $(n=68), \% 67,7$ 'si 31 yaş ve üzeri $(n=64)$ olduğu, \%29,5'inin $(\mathrm{n}=64)$ milli sporcu ve \%70,5'inin $(\mathrm{n}=153)$ milli sporcu olmadiğ 1 , \%22,1'inin (n=147) 10 yıl ve 10 yıldan az, \%10,1'inin $(n=48)$ 11-20 yıl arası, \%40,9'unun $(n=22) 21$ yıl ve üzeri zamandır spor yaptığ1, \%31,3'ünün 16,5-18,5 (n=68), \%53,5'inin $(n=116)$ 18,51-25, \%15,2'isinin $(n=33)$ ise 25,01-30 VKİ aralığında olduğu, \%10,6'sının $(n=23)$ ilkokul, \%25,8'inin $(n=56)$ ortaokul, \%32,7'sinin $(n=71)$ lise, \%25,3'ünün $(n=55)$ lisans ve \%5,5'inin ( $n=12)$ lisansüstü eğitim düzeyinde olduğu görülmektedir.

Tablo 2: Katılımcıların cinsiyet değişkenine göre beslenme tutumlarının karşılaştırılması

\begin{tabular}{|c|c|c|c|c|c|c|c|}
\hline Alt Boyutlar & $\underset{t}{\text { Cinsiye }}$ & $\mathbf{N}$ & $\overline{\mathbf{X}}$ & Ss & $\mathbf{T}$ & df & $\mathbf{p}$ \\
\hline \multirow{2}{*}{$\begin{array}{c}\text { Beslenme Hakkında } \\
\text { Bilgi }\end{array}$} & Erkek & 157 & 20,59 & 3,48 & \multirow{2}{*}{$-1,526$} & \multirow{2}{*}{215} & \multirow{2}{*}{,128 } \\
\hline & Kadın & 60 & 21,38 & 3,24 & & & \\
\hline \multirow{2}{*}{ Kötü Beslenme } & Erkek & 157 & 19,64 & 3,69 & \multirow{2}{*}{,440 } & \multirow{2}{*}{215} & \multirow{2}{*}{,661 } \\
\hline & Kadın & 60 & 19,40 & 3,54 & & & \\
\hline \multirow{2}{*}{ Olumlu Beslenme } & Erkek & 157 & 19,33 & 3,85 & \multirow{2}{*}{, 821} & \multirow{2}{*}{215} & \multirow{2}{*}{,413 } \\
\hline & Kadın & 60 & 18,85 & 3,89 & & & \\
\hline \multirow{2}{*}{$\begin{array}{c}\text { Beslenmeye Yönelik } \\
\text { Duygu }\end{array}$} & Erkek & 157 & 19,00 & 3,77 & \multirow{2}{*}{,710 } & \multirow{2}{*}{215} & \multirow{2}{*}{,479 } \\
\hline & Kadın & 60 & 18,62 & 2,92 & & & \\
\hline \multirow{2}{*}{$\begin{array}{c}\text { SBİTÖ Toplam } \\
\text { Puan }\end{array}$} & Erkek & 157 & 78,57 & 10,07 & \multirow{2}{*}{,209 } & \multirow{2}{*}{215} & \multirow{2}{*}{, 835} \\
\hline & Kadın & 60 & 78,25 & 9,83 & & & \\
\hline
\end{tabular}


Tablo 2'ye bakıldığında, katılımcıların cinsiyetleri arasında herhangi bir istatistiksel anlamlılığa rastlanmamıştır ( $\mathrm{p}>0,05)$.

Tablo 3: Katılımcıların millilik değişkenine göre beslenme tutumlarının karşılaşstırılması

\begin{tabular}{|c|c|c|c|c|c|c|c|}
\hline Alt Boyutlar & Millilik & $\mathbf{N}$ & $\overline{\mathbf{X}}$ & Ss & $\mathbf{T}$ & df & $\mathbf{p}$ \\
\hline \multirow{2}{*}{$\begin{array}{l}\text { Beslenme Hakkında } \\
\text { Bilgi }\end{array}$} & Evet & 64 & 21,30 & 3,17 & \multirow{2}{*}{1,354} & \multirow{2}{*}{215} & \multirow{2}{*}{,177 } \\
\hline & Hayır & 153 & 20,61 & 3,52 & & & \\
\hline \multirow{2}{*}{ Kötü Beslenme } & Evet & 64 & 19,02 & 4,01 & \multirow{2}{*}{$-1,470$} & \multirow{2}{*}{215} & \multirow{2}{*}{, 143} \\
\hline & Hayır & 153 & 19,81 & 3,46 & & & \\
\hline \multirow{2}{*}{ Olumlu Beslenme } & Evet & 64 & 19,63 & 3,89 & \multirow{2}{*}{1,054} & \multirow{2}{*}{215} & \multirow{2}{*}{,293 } \\
\hline & Hayır & 153 & 19,02 & 3,85 & & & \\
\hline \multirow{2}{*}{$\begin{array}{l}\text { Beslenmeye Yönelik } \\
\text { Duygu }\end{array}$} & Evet & 64 & 18,78 & 3,85 & \multirow{2}{*}{,- 302} & \multirow{2}{*}{215} & \multirow{2}{*}{,763 } \\
\hline & Hayır & 153 & 18,94 & 3,43 & & & \\
\hline \multirow{2}{*}{$\begin{array}{l}\text { SBİTÖ Toplam } \\
\text { Puan }\end{array}$} & Evet & 64 & 78,72 & 10,43 & \multirow{2}{*}{, 228} & \multirow{2}{*}{215} & \multirow{2}{*}{,820 } \\
\hline & Hayır & 153 & 78,38 & 9,83 & & & \\
\hline
\end{tabular}

Tablo 3'e göre, millik durumu değişkenine göre herhangi bir istatistiksel anlamlı farklılık saptanmamıştır $(\mathrm{p}>0,05)$.

Tablo 4: Katılımcıların yaş değişkenine göre beslenme tutumlarının karşıllaştırılması

\begin{tabular}{|c|c|c|c|c|c|c|c|}
\hline $\begin{array}{c}\text { Alt } \\
\text { Boyutlar }\end{array}$ & Yaş & $\mathbf{N}$ & $\overline{\mathbf{X}}$ & Ss & $\mathbf{F}$ & $\mathbf{P}$ & LSD \\
\hline \multirow{3}{*}{$\begin{array}{l}\text { Beslenme } \\
\text { Hakkında } \\
\text { Bilgi }\end{array}$} & 20 Yaş Altı & 128 & 20,43 & 3,34 & \multirow{3}{*}{5,515} & \multirow{3}{*}{, $005 *$} & \multirow{3}{*}{$\begin{array}{c}20 \text { Yaş Altı }<21-30 \\
\text { Yaş Üstü } \\
20 \text { Yaş Altı }>31 \text { Yaş } \\
\text { Üstü }\end{array}$} \\
\hline & $\begin{array}{c}\text { 21-30 Yaş } \\
\text { Arası }\end{array}$ & 68 & 21,88 & 3,31 & & & \\
\hline & 31 Yaş Üstü & 21 & 19,67 & 3,61 & & & \\
\hline \multirow{3}{*}{$\begin{array}{l}\text { Kötü } \\
\text { Beslenme }\end{array}$} & 20 Yaş Altı & 128 & 19,45 & 3,58 & \multirow{3}{*}{, 283} & \multirow{3}{*}{, 754} & \\
\hline & $\begin{array}{c}\text { 21-30 Yaş } \\
\text { Arası }\end{array}$ & 68 & 19,68 & 3,98 & & & \\
\hline & 31 Yaş Üstü & 21 & 20,05 & 2,91 & & & \\
\hline \multirow{3}{*}{$\begin{array}{l}\text { Olumlu } \\
\text { Beslenme }\end{array}$} & 20 Yaş Altı & 128 & 19,40 & 3,86 & \multirow{3}{*}{2,617} & \multirow{3}{*}{, 075} & \\
\hline & $\begin{array}{c}\text { 21-30 Yaş } \\
\text { Arası }\end{array}$ & 68 & 19,38 & 3,46 & & & \\
\hline & 31 Yaş Üstü & 21 & 17,38 & 4,73 & & & \\
\hline \multirow{3}{*}{$\begin{array}{l}\text { Beslenmeye } \\
\text { Yönelik } \\
\text { Duygu }\end{array}$} & 20 Yaş Altı & 128 & 18,50 & 3,24 & \multirow{3}{*}{3,330} & \multirow{3}{*}{, $038 *$} & 20 Yaş Alți<21-30 \\
\hline & $\begin{array}{c}\text { 21-30 Yaş } \\
\text { Arası }\end{array}$ & 68 & 19,12 & 3,96 & & & $\begin{array}{c}\text { Yaş Üstü } \\
31 \text { Yaş Üstü>20 Yaş } \\
\text { Altı }\end{array}$ \\
\hline & 31 Yaş Üstü & 21 & 20,57 & 3,61 & & & \\
\hline \multirow{3}{*}{$\begin{array}{l}\text { SBİTÖ } \\
\text { Toplam } \\
\text { Puan }\end{array}$} & 20 Yaş Altı & 128 & 77,77 & $\begin{array}{c}10,1 \\
2\end{array}$ & \multirow{3}{*}{1,243} & \multirow{3}{*}{,291 } & \\
\hline & $\begin{array}{c}\text { 21-30 Yaş } \\
\text { Arası }\end{array}$ & 68 & 80,06 & $\begin{array}{c}10,5 \\
2 \\
\end{array}$ & & & \\
\hline & 31 Yaş Üstü & 21 & 77,67 & 6,57 & & & \\
\hline
\end{tabular}

${ }^{*} \mathrm{p}<0,05$ 
Tablo 4 incelendiğinde; “'beslenme hakkında bilgi” alt boyutu ve ' beslenmeye yönelik duygu" alt boyutlarında istatiksel olarak anlamlı farklılıklar görülürken $(p<0,05)$, kötü beslenme, olumlu beslenme ve SBİTÖ toplam puanında herhangi bir anlamlı farklılık görülmemektedir $(\mathrm{p}>0,05)$.

Tablo 5: Katılımcıların spor yaşı değişkenine göre beslenme tutumlarının karşılaştırılması

\begin{tabular}{|c|c|c|c|c|c|c|c|}
\hline $\begin{array}{c}\text { Alt } \\
\text { Boyutlar }\end{array}$ & Spor Yaşı & $\mathbf{N}$ & $\overline{\mathbf{X}}$ & Ss & $\mathbf{F}$ & $\mathbf{P}$ & LSD \\
\hline \multirow{3}{*}{$\begin{array}{l}\text { Beslenme } \\
\text { Hakkında } \\
\text { Bilgi }\end{array}$} & 10 Y1l Alt1 & 147 & 20,46 & 3,43 & \multirow{3}{*}{3,817} & \multirow{3}{*}{, $024 *$} & \multirow{3}{*}{$\begin{array}{c}11-20 \text { Y}_{11} \\
\text { Aras1 }>10 Y_{1} 1 \text { Alt }\end{array}$} \\
\hline & $\begin{array}{c}\text { 11-20 Y1l } \\
\text { Aras1 }\end{array}$ & 48 & 22,00 & 2,96 & & & \\
\hline & 21 Y1l Üzeri & 22 & 20,55 & 3,88 & & & \\
\hline \multirow{3}{*}{$\begin{array}{l}\text { Kötü } \\
\text { Beslenme }\end{array}$} & 10 Y1l Alt1 & 147 & 19,58 & 3,47 & \multirow{3}{*}{,673 } & \multirow{3}{*}{,511 } & \\
\hline & $\begin{array}{c}\text { 11-20 Y1l } \\
\text { Aras1 }\end{array}$ & 48 & 19,23 & 4,45 & & & \\
\hline & 21 Y1l Üzeri & 22 & 20,32 & 2,70 & & & \\
\hline \multirow{3}{*}{$\begin{array}{l}\text { Olumlu } \\
\text { Beslenme }\end{array}$} & 10 Y1l Alt1 & 147 & 19,13 & 3,82 & \multirow{3}{*}{1,012} & \multirow{3}{*}{,365 } & \\
\hline & $\begin{array}{c}\text { 11-20 Y1l } \\
\text { Aras1 }\end{array}$ & 48 & 19,77 & 3,18 & & & \\
\hline & 21 Yil Üzeri & 22 & 18,41 & 5,26 & & & \\
\hline \multirow{3}{*}{$\begin{array}{l}\text { Beslenmeye } \\
\text { Yönelik } \\
\text { Duygu }\end{array}$} & 10 Y1l Alt1 & 147 & 18,67 & 3,33 & \multirow{3}{*}{2,310} & \multirow{3}{*}{, 102} & \\
\hline & $\begin{array}{c}\text { 11-20 Y11 } \\
\text { Aras1 }\end{array}$ & 48 & 18,88 & 4,01 & & & \\
\hline & 21 Y1l Üzeri & 22 & 20,41 & 3,76 & & & \\
\hline \multirow{3}{*}{$\begin{array}{l}\text { SBİTÖ } \\
\text { Toplam } \\
\text { Puan }\end{array}$} & 10 Y1l Alt1 & 147 & 77,84 & 10,01 & \multirow{3}{*}{1,243} & \multirow{3}{*}{,398 } & \\
\hline & $\begin{array}{c}\text { 11-20 Y1l } \\
\text { Aras1 }\end{array}$ & 48 & 79,88 & 10,99 & & & \\
\hline & 21 Y1l Üzeri & 22 & 79,68 & 7,01 & & & \\
\hline
\end{tabular}

*p $<0,05$

Tablo 5 incelendiğinde; "beslenme hakkında bilgi'" alt boyutunda istatiksel olarak anlamlı farklılık görülürken ( $\mathrm{p}<0,05)$, kötü beslenme, olumlu beslenme, beslenmeye yönelik duygu ve SBİTÖ toplam puanında herhangi bir anlamlı farklılık görülmemektedir ( $>00,05)$.

Tablo 6: Katılımcıların VKİ değişkenine göre beslenme tutumlarının karşılaştırılması

\begin{tabular}{|c|c|c|c|c|c|c|c|}
\hline $\begin{array}{c}\text { Alt } \\
\text { Boyutlar }\end{array}$ & VKİ & $\mathbf{N}$ & $\overline{\mathbf{X}}$ & Ss & $\mathbf{F}$ & $\mathbf{P}$ & LSD \\
\hline \multirow{3}{*}{$\begin{array}{l}\text { Beslenme } \\
\text { Hakkında } \\
\text { Bilgi }\end{array}$} & $\begin{array}{l}16,5- \\
18,5\end{array}$ & 68 & 20,82 & 3,26 & \multirow{3}{*}{,010 } & \multirow{3}{*}{,990 } & \\
\hline & $18,51-25$ & 116 & 20,78 & 3,60 & & & \\
\hline & $25,01-30$ & 33 & 20,88 & 3,23 & & & \\
\hline $\begin{array}{l}\text { Kötü } \\
\text { Beslenme }\end{array}$ & $\begin{array}{c}16,5- \\
18,5\end{array}$ & 68 & 19,88 & 3,16 &, 743 & ,477 & \\
\hline
\end{tabular}




\begin{tabular}{|c|c|c|c|c|c|c|}
\hline & $18,51-25$ & 116 & 19,58 & 3,89 & & \\
\hline & $25,01-30$ & 33 & 18,94 & 3,71 & & \\
\hline \multirow{3}{*}{$\begin{array}{l}\text { Olumlu } \\
\text { Beslenme }\end{array}$} & $\begin{array}{c}16,5- \\
18,5\end{array}$ & 68 & 19,82 & 4,01 & \multirow{3}{*}{1,533} & \multirow{3}{*}{,218 } \\
\hline & $18,51-25$ & 116 & 19,03 & 3,78 & & \\
\hline & $25,01-30$ & 33 & 18,52 & 3,76 & & \\
\hline \multirow{3}{*}{$\begin{array}{l}\text { Beslenmeye } \\
\text { Yönelik } \\
\text { Duygu }\end{array}$} & $\begin{array}{c}16,5- \\
18,5 \\
\end{array}$ & 68 & 18,66 & 3,17 & \multirow{3}{*}{,265 } & \multirow{3}{*}{, 767} \\
\hline & $18,51-25$ & 116 & 18,95 & 3,54 & & \\
\hline & $25,01-30$ & 33 & 19,18 & 4,36 & & \\
\hline \multirow{3}{*}{$\begin{array}{l}\text { SBİTÖ } \\
\text { Toplam } \\
\text { Puan }\end{array}$} & $\begin{array}{c}16,5- \\
18,5\end{array}$ & 68 & 79,19 & 9,63 & \multirow{3}{*}{,336 } & \multirow{3}{*}{, 715} \\
\hline & $18,51-25$ & 116 & 78,34 & 10,19 & & \\
\hline & $25,01-30$ & 33 & 77,52 & 10,19 & & \\
\hline
\end{tabular}

${ }^{*} \mathrm{p}<0,05$

Tablo 6 incelendiğinde; katılımcıların vücut kitle indeksi değişkenine göre beslenme tutumlarında istatiksel olarak herhangi bir farklılık görülmemektedir ( $>00,05)$.

Tablo 7: Katılımcıların eğitim durumu değişkenine göre beslenme tutumlarının karşılaştırılması

\begin{tabular}{|c|c|c|c|c|c|c|c|}
\hline $\begin{array}{c}\text { Alt } \\
\text { Boyutlar }\end{array}$ & $\begin{array}{c}\text { Eğitim } \\
\text { Durumu }\end{array}$ & $\mathbf{N}$ & $\overline{\mathbf{X}}$ & Ss & $\mathbf{F}$ & $\mathbf{P}$ & LSD \\
\hline \multirow{5}{*}{$\begin{array}{l}\text { Beslenme } \\
\text { Hakkında } \\
\text { Bilgi }\end{array}$} & İlkokul & 23 & 20,57 & 3,78 & \multirow{5}{*}{2,278} & \multirow{5}{*}{, 062} & \\
\hline & Ortaokul & 56 & 20,27 & 3,38 & & & \\
\hline & Lise & 71 & 20,45 & 3,48 & & & \\
\hline & Lisans & 55 & 21,47 & 3,35 & & & \\
\hline & Lisansüstü & 12 & 22,92 & 1,73 & & & \\
\hline \multirow{5}{*}{$\begin{array}{l}\text { Olumlu } \\
\text { Beslenme }\end{array}$} & İlkokul & 23 & 21,22 & 2,75 & \multirow{5}{*}{2,233} & \multirow{5}{*}{,067 } & \\
\hline & Ortaokul & 56 & 19,61 & 3,63 & & & \\
\hline & Lise & 71 & 18,77 & 3,57 & & & \\
\hline & Lisans & 55 & 19,73 & 3,70 & & & \\
\hline & Lisansüstü & 12 & 20,33 & 4,52 & & & \\
\hline \multirow{5}{*}{$\begin{array}{l}\text { Olumlu } \\
\text { Beslenme }\end{array}$} & İlkokul & 23 & 20,43 & 3,59 & \multirow{5}{*}{,979 } & \multirow{5}{*}{,420 } & \\
\hline & Ortaokul & 56 & 19,25 & 4,52 & & & \\
\hline & Lise & 71 & 18,68 & 3,88 & & & \\
\hline & Lisans & 55 & 19,18 & 3,09 & & & \\
\hline & Lisansüstü & 12 & 19,75 & 4,09 & & & \\
\hline \multirow{5}{*}{$\begin{array}{l}\text { Beslenmey } \\
\text { e Yönelik } \\
\text { Duygu }\end{array}$} & İlkokul & 23 & 20,17 & 3,76 & \multirow{5}{*}{2,039} & \multirow{5}{*}{,090 } & \\
\hline & Ortaokul & 56 & 18,98 & 3,11 & & & \\
\hline & Lise & 71 & 18,04 & 3,47 & & & \\
\hline & Lisans & 55 & 19,22 & 3,48 & & & \\
\hline & Lisansüstü & 12 & 19,58 & 5,07 & & & \\
\hline \multirow{3}{*}{$\begin{array}{l}\text { SBİTÖ } \\
\text { Toplam } \\
\text { Puan }\end{array}$} & İlkokul & 23 & 82,39 & 9,11 & \multirow{3}{*}{2,2818} & \multirow{3}{*}{, $026 *$} & İlkokul>Lis \\
\hline & Ortaokul & 56 & 78,11 & $\begin{array}{c}11,2 \\
9\end{array}$ & & & $\begin{array}{c}\mathrm{e} \\
\text { Lisans }>\text { Lise }\end{array}$ \\
\hline & Lise & 71 & 75,94 & 8,36 & & & Lisansüstü> \\
\hline
\end{tabular}




\begin{tabular}{cccc} 
Lisans & 55 & 79,60 & 9,48 \\
\hline Lisansüstü & 12 & 82,58 & $\begin{array}{c}13,0 \\
0\end{array}$
\end{tabular}

Lise

$* \mathrm{p}<0,05$

Tablo 7 incelendiğinde; beslenme hakkında bilgi, kötü beslenme, olumlu beslenme, beslenmeye yönelik duygu alt boyutlarında istatiksel farklılı̆ga rastlanmazken $(p>0,05)$ “'SBİTÖ toplam puanında'” istatiksel olarak anlamlı farklılık saptanmıştır $(\mathrm{p}<0,05)$.

\section{TARTIŞMA VE SONUÇ}

$\mathrm{Bu}$ çalışma, taekwondo sporcularının çeşitli değişkenler açısından sağlıklı beslenmeye ilişkin tutumlarının belirlenmesi amacıyla yapılmıştır.

Yapılan analizler sonucuna göre taekwondo sporcularının sağlıklı beslenmeye ilişkin tutumlarının belirlenmesinde yaş değişkenine göre "'beslenme hakkında bilgi' alt boyutu ve “'beslenmeye yönelik duygu” alt boyutlarında istatiksel olarak anlamlı farklılıklar görülürken, kötü beslenme, olumlu beslenme ve SBİTÖ toplam puanında herhangi bir anlamlı farklılık göstermediği saptanmıştır. Benzer şekilde, Ceylan ve diğerleri (2020) COVID-19 salgını kilitlenmesi sırasında sağlıklı beslenme tutumları ve davranışları belirlemek amacıyla yaptığı çalışmada, yaş değişkenine göre "beslenme hakkında bilgi'” alt boyutunda istatistiki olarak anlamlılık saptanmazken, diğer alt boyutlarda ise istatistiki olarak anlamlı farklılıklar tespit edilmiştir.. Hendire ve diğerleri (2008) 18-35 yaş ile 35 yaş üstü bireyleri karşılaştırdığı bir araştırmada, beslenme bilgisi, 35 yaş üstü kişilerin bulunduğu grupta 18-35 yaş grubuna göre daha yüksek olduğu görülmüştür. De Vriendt ve diğerleri (2008) 803 Belçikalı kadının katılımıyla yapmış olduğu çalışmada, yaş aralığı 18-39 olmasına rağmen kadınların beslenme konusundaki bilgileri ile yaş arasında anlamlı farklılıklar görülmüştür ve yaş arttıkça beslenme bilgisinin paralel olarak arttığı bulunmuştur. Cockburn ve diğerleri (2014) antrenörün sporcu beslenmesi hakkında bilgi düzeyinin incelediği bir araştırmada, 51 yaş ve üzeri olan kişilerin puanları diğerlerinden daha yüksek görülmüş ve çalışmamızla paralellik gösterdiği göstermektedir. Özenoğlu (2021), SBİTÖ toplam puanı ile yaş değişkeni arasında pozitif yönde anlamlı farklılıklar bulmuştur. 
Yapılan çalışmada taekwondo sporcularının Sağlıklı beslenmeye ilişkin tutumlarının belirlenmesinde cinsiyet değişkenine göre bakıldığında, beslenmeye ilişkin tutumlarının alt boyutlarında istatistiksel olarak anlamlılık saptanmamıştır. Taekwondo sıklet sporu olmasından dolayı sporcuların sürekli olarak kilolarını kontrol etmesi gerekmektedir. Kilo kontrolünün beslenmeden geçtiğinin farkında olmalarından dolayı taekwondo sporcularında cinsiyete göre beslenme bilgilerinde anlamlı bir fark olmadığı söylenebilir. Bu çalışmaya benzer şekilde, Özenoğlu ve diğerleri (2021) yetişkin bireylerin beslenme okuryazarlı̆̆ bilgi düzeylerini belirlemek ve bunun, sağlıklı beslenmeyle ilişkin tutumlar ve Beden Kütle İndeksi (BKİ) ile ilişkisinin araştırılması amacıyla yaptıkları çalışmada, "beslenme hakkında bilgi" alt boyutunda kadınlar lehine istatistiksel olarak anlamlı bir farka rastlanırken, "beslenmeye yönelik duygu" alt boyutunda ise erkekler lehine istatistiksel olarak anlamlı bir farka rastlanırken diğer alt boyutlarında cinsiyet değişkenine göre anlamlı bir fark olmadığı tespit edilmiştir.

Yapılan literatür taramasında beslenme okuryazarlı̆̆ı, beslenme davranışı ve beslenme kalitesi puanlarının kadınlarda daha yüksek değerlere sahip olduğunu gösteren çalışmalara rastlanılmıştır. (Cesur ve diğerleri, 2015; Şanlıer ve diğerleri, 2009; Çelik, 2017 ve Murathan, 2013). Bir diğer çalışmada, Mirmiran ve diğerleri (2007) beslenme bilgisi konusunda erkeklerin kadınlardan daha az puana sahip olduğu görülmüştür fakat kadınların erkeklere karşı daha kötü beslenme alışkanlıkları sergilediği görülmüş̧ür.

Yapılan çalışmada taekwondo sporcularının Sağlıklı beslenmeye ilişkin tutumlarının belirlenmesinde millilik değişkenine bakıldığında, beslenmeye ilişkin tutumların alt boyutlarında istatistiksel olarak anlamlı bir fark göstermediği tespit edilmiştir ( $p>0,05)$. Üstün ve diğerleri (2020) sporcu ve sedanter olan üniversite öğrencilerinin beslenme tutumlarının belirlenmesi amacıyla yaptı̆̆ çalışmada, istatistiksel olarak anlamlı bir farklılığa rastlanılmamıştır. Kırkbir (2020) sporcularda sağlıklı beslenme ile mutluluk arasındaki ilişkiyi belirlemek amacıyla yaptığı çalışmada, sporculuk düzeyi değişkenine göre yapılan analizlerde "beslenmeye yönelik duygu" alt boyutunda anlamlı bir farkl1lık görülmezken, diğer alt boyutlarda ise profesyonel sporcular lehine anlamlı farkl11ıklar görülmüştür.

Üstün (2020) sporcu olan ve sporcu olmayan üniversite öğrencileri üzerinde sosyal fiziksel kaygı ve beslenme tutumu arasındaki ilişkiyi belirlemek amacıyla yaptığı çalışmada, 
spor yapan öğrencilerin "pozitif beslenme" alt boyutunda anlamlı farkl1lık oluştururken "kötü beslenme" alt boyutunda ise spor yapmayan öğrenciler anlamlı farklılık oluşturmuştur.

Sağlkklı beslenmeye ilişkin tutumlarının belirlenmesinde spor yaşı değişkenine göre bakıldığında, beslenmeye ilişkin tutumların "beslenme hakkında bilgi" alt boyutunda bir farka rastlanırken $(\mathrm{p}<0,05)$, diğer alt boyutlarda ise istatistiksel olarak anlamlı bir farka rastlanılmamıştır. "Beslenme hakkında bilgi" alt boyutunda 11-20 yıl arası spor yapma yılı olan taekwondo sporcularının müsabaka öncesi kilo alıp vermede geçmiş yıllara göre tecrübe edindiği ve kilolarını daha iyi ayarlayabilmeleri için beslenme hakkındaki bilgilerini geliştirdikleri düşünülmektedir. Yapılan literatür taraması sonucunda spor yaşı değişkeninin değerlendirildiği beslenme tutumunu ölçen bir çalışmaya rastlanılmamıştır.

Yapılan çalı̧̧mada taekwondo sporcularının Sağlıklı beslenmeye ilişkin tutumlarının belirlenmesinde VKİ değişkenine göre bakıldığında, beslenmeye ilişkin tutumların alt boyutlarında istatistiksel olarak anlamlı bir farka rastlanılmamıştır. Bu çalışmamıza benzer olarak, Özenoğlu ve diğerleri (2021), yaptığı çalışmada VKİ ve SBİTÖ toplam puan karşılaştırması sonucunda istatistiksel olarak anlamlı sonuçlara rastlamamıştır. Duralı (2019) yaptı̆̆ çalışmada, katılımcıların VKİ sınıflarına göre beslenme bilgi skorları ve besin tercihi skorları arasında anlamlı fark bulunamamıştı. Bunların aksine Mearns ve diğgerleri (2017) Yeni Zelanda'da 103 sağlık öğrencisi üzerinde yaptığı bir araştırmada, beslenme okuryazarlık puanları ile antropometrik ölçümler (VKİ, vücut yağ yüzdesi) arasında ters ilişsi bulunmuştur.

Sağlıklı beslenmeye ilişkin tutumlarının belirlenmesinde eğitim durumları değişkenine göre bakıldığında, beslenmeye ilişkin tutumların alt boyutlarında istatistiksel olarak anlamlı bir farka rastlanılmazken ( $>>0,05)$, SBİTÖ toplam puanlarında ise "Lisansüstü Eğitim" lehine istatistiksel olarak anlamlı bir farklılık bulunmuştur $(p<0,05)$. Sporcuların eğitim seviyelerinin artması sağlıklı beslenmeye ilişkin tutumlarını olumlu yönde etkilediği söylenebilir. Bu çalışmaya benzer olarak, Özenoğlu ve diğerleri (2021) yetişkinlerde beslenme okuryazarlığı düzeyini tespit etmek ve bunun, sağlıklı beslenmeye ilişkin tutumlar ve Beden Kütle İndeksi (BKI) ile ilişkisinin araştırılması amacıyla yaptıkları çalışmada, eğitim durumlarının "beslenmeye yönelik duygu" alt boyutunda istatistiksel olarak anlamlı bir farklılık oluşturduğunu belirtmiştir. Ceylan ve diğerleri (2020) COVID-19 salgını kilitlenmesi sırasında sağlıklı beslenme tutumları ve davranışları belirlemek amacıyla yaptığı çalışmada, eğitim 
durumları değişkenine göre "beslenme hakkında bilgi" alt boyutunda üniversite eğitimi lehine anlamlı farklılıklara rastlanılmıştır.

Sonuç olarak elde ettiğimiz sonuçlara göre literatürde çalışmamızla paralellik gösteren ve çalışmamızı destekler nitelikte çalışmaların da bulunduğu söylenebilir. Elde edilen veriler ışığında ve literatürdeki araştırmalar göz önüne alındığında katılımcıların sağlıklı beslenmeye ilişkin tutumlarında cinsiyet, millilik, vücut kitle indeksi değişkenlerinin beslenmeye yönelik tutumlarını etkilemediği ancak eğitim durumu, yaş ve spor yapma yılı değişkenlerinin tecrübeye esas değişkenler olduğundan dolayı katılımcıların beslenmeye yönelik tutumlarında farkl11kklara neden olduğu söylenebilir.

Bu kapsamda çalışmamızın doğrultusunda aşağıdaki önerilerde bulunulabilir;

Taekwondo sporunun bir sıklet sporu olması dolayısıyla sporcuların kilolarını sürekli sabit tutmaları gerekmektedir bu yüzden taekwondo sporcularının bir diyetisyen eşliğinde bilgilendirilebilir.

Taekwondo antrenörlük seminerlerinde antrenörlere beslenme hakkında daha kapsamlı bilgilendirmeler yapılabilir.

Çalışmamız diğer sıklet sporu olan branşlara uyarlanabilir.

\section{KAYNAKÇA}

Akıncı, A,Y. (2018). Eski Çağlarda Atletler (Sporcular): Eğitim, Antrenman, Beslenme ve Sporcu Yetiştirme Geleneği. Doktora Tezi, Süleyman Demirel Üniversitesi Sosyal Bilimler Enstitüsü Tarih Anabilim Dalı. Isparta.

Cesur, B., Koçoğlu, G. \& Sümer, H. (2015). Evaluation instrument of nutrition literacy on adults (EINLA) A validity and reliability study. Integrative Food, Nutrition And Metabolism, 2(1), 127-130.

Ceylan, V., Muştu, Ç. \& Sarışık, M. (2020). Healthy Nutritional Attitudes and Behaviors During COVID-19 Outbreak Lockdown. Journal of Tourism and Gastronomy Studies, 8(4), 2491-2506. DOI: 10.21325/jotags.2020.723

Cockburn, E., Fortune, A., Briggs, M. \& Rumbold, P. (2014). Nutritional knowledge of UK coaches. Nutrients, 6(4), 1442-1453. Doi: https://doi.org/10.3390/nu6041442

Çelik, S. (2017). Bir tıp fakültesi öğrencilerinde fiziksel aktivite ve beslenme alışkanlıklarının değerlendirilmesi. Uzmanlık Tezi. Marmara Üniversitesi, Tıp Fakültesi, Halk Sağlığı Anabilim Dal, İstanbul. 
De Vriendt, T., Matthys, C., Verbeke, W., Pynaert, I., \& De Henauw, S. (2009). Determinants of nutrition knowledge in young and middle-aged Belgian women and the association with their dietary behaviour. Appetite, 52(3), 788-792. https://doi.org/10.1016/j.appet.2009.02.014

Duralı, Ö. (2019). Yetişkin kadın bireylerde beslenme bilgi düzeyinin ve beslenme durumunun saptanması. Yüksek lisans tezi. Trakya Üniversitesi, Sağlık Bilimleri Enstitüsü, Edirne.

Durmaz, Ş., Kaçar, Z., Can, S., Koca, R. ve Yeşilova, D. (2007). Çanakkale Sağlık Yüksekokulu Öğrencilerinin Problem Çözme Becerileri ve Etkileyen Bazı Faktörler. Atatürk Üniversitesi Hemşirelik Yüksekokulu Dergisi, 10 (4), 63-71.

Ersoy, G., Alper,R., Kargül, A.; Yüzücü Beslenmesi, Yüzme, Atlama ve Su Topu Federasyonu Yayın1, 1987.

Garibağaoğlu, M., Budak, N., Öner, N., Sağlam, Ö. ve Nişli, K. (2006). Üç farklı üniversitede eğitim gören kız öğrencilerin beslenme durumları ve vücut ağırlıklarının değerlendirmesi, Sağlık Bilimleri Dergisi, 15(3), 173-180.

Günay, M., Cicioğlu, I. (2001). Spor Fizyolojisi. Gazi Kitapevi, Ankara.

Hendrie, G. A., Coveney, J., \& Cox, D. (2008). Exploring nutrition knowledge and the demographic variation in knowledge levels in an Australian community sample. Public Health Nutrition, 11(12), 1365-1371. DOI:

https://doi.org/10.1017/S1368980008003042

Heşeminia, T., Çalışkan, D., ve Işık, A. (2002). Ankara' da yüksek öğretim öğrenci yurtlarında kalan öğrencilerin beslenme sorunları. İbni Sina Tıp Dergisi 7: 155- 166

İnceoğlu, M. (2010). Tutum Algı İletişim, Beykent Üniversitesi Yayınları No: 69, 5. Baskı, İstanbul

Kırkbir, F. (2020). Sporcularda Sağlıklı Beslenme İle Mutluluk Arasındaki İlişkinin İncelenmesi.Spor Eğitim Dergisi, 4(2),125-130. Retrieved from https://dergipark.org.tr/en/pub/seder/issue/54136/749319

Mearns, G. J., Chepulis, L., Britnell, S., \& Skinner, K. (2017). Health and nutritional literacy of New Zealand nursing students. Journal of Nursing Education, 56(1), 43-48. Doi: https://doi.org/10.3928/01484834-20161219-09

Mirmiran, P., Azadbakht, L. \& Azizi, F. (2007). Dietary behaviour of Tehranian adolescents does not accord with their nutritional knowledge. Public health nutrition, 10(9), 897901.DOI: https://doi.org/10.1017/S1368980007246701

Murathan, F. (2013). Üniversite öğrencilerinde obezite sıklığı, fiziksel aktivite düzeyi ve sağlıklı yaşam biçimi davranışlarının incelenmesi. Doktora tezi. Fırat Üniversitesi, Sağlık Bilimleri Enstitüsü, Elazığ.

Şanlıer, N., Konaklığlu, E. \& Güçer, E. (2009). Gençlerin beslenme bilgi, alışkanlık ve davranışları ile beden kütle indeksleri arasındaki ilişki. Gazi Üniversitesi Gazi Eğitim Fakültesi Dergisi, 29(2), 333-352.

Tabachnick and Fidell, 2013 B.G. Tabachnick, L.S. Fidell Using Multivariate Statistics (sixth ed.)Pearson, Boston (2013) 
TC Sağlık Bakanlığı Türkiye Beslenme Rehberi -TÜBER- (2015). Sağlık Bakanlığı Yayınları, Ankara.

Tekkurşun Demir, G., Cicioğlu, Hİ., (2019). Sağlıklı Beslenmeye İlişkin Tutum Ölçeği (SBİTÖ):Geçerlik ve Güvenirlik Çalışması. Gaziantep Üniversitesi Spor Bilimleri Dergisi,4(2),256-274.DOI: 10.31680/gaunjss.559462.

Thomas, D. T., Erdman, K. A., and Burke, L. M. (2016). American college of sports medicine joint position statement. nutrition and athletic performance. Medicine \& Science Sports \& Exercise, 48(3), 543-568.

Özdemir, G. (2010). Spor dallarına göre beslenme. Spormetre beden eğitimi ve spor bilimleri dergisi, 8(1), 1-6. https://doi.org/10.1501/Sporm_0000000169

Özenoğlu, A., Beyza, G. Ü. N., Karadeniz, B., Fatma, K. O. Ç., Bilgin, V., Bembeyaz, Z., \& Saha, B. S. (2021). Yetişkinlerde beslenme okuryazarlığın sağlıklı beslenmeye ilişkin tutumlar ve beden kütle indeksi ile ilişkisi.Life Sciences, 16(1), 1-18. Retrieved from https://dergipark.org.tr/en/pub/nwsals/issue/59902/770776 